\title{
Comparative Study of Chemical Composition of the Halophyte Species Native to the Persian (Arabian) Gulf
}

\author{
Iwona Cybulska, ${ }^{\mathrm{a}, \mathrm{b} *}$ Grzegorz P. Brudecki, ${ }^{\mathrm{a}, \mathrm{e}}$ J. Jed Brown, ${ }^{\mathrm{a}, \mathrm{c}}$ Laura S. S. Hulkko, ${ }^{\mathrm{d}}$ \\ Sumaya Al Hosani, and Mette H. Thomsen ${ }^{\mathrm{a}, \mathrm{d}}$
}

\begin{abstract}
Extensive comparative characterization was performed to explore halophytes native to the Persian (Arabian) Gulf. Ten species collected from the Western region of Abu Dhabi, United Arab Emirates (UAE) were analyzed for their lignocellulosic components as well as for ash and extractives content. It was found that the species significantly differ in the content of carbohydrates, lignin, total ash-free extractives and total ash. The total ash content was found to negatively influence the content of carbohydrates. Based on the characteristics, it is concluded that Cornulaca aucheri is the most attractive as a source of carbohydrates, and Tetraena (Zygophyllum) qatarensis has the potential to produce the highest yield of the extractives fraction.
\end{abstract}

Keywords: Halophytes; Biomass characterization; Extractives; Biorefinery; Second generation feedstock

Contact information: a: Khalifa University, P.O. Box 127788, Abu Dhabi, United Arab Emirates (formerly Masdar Institute of Science and Technology), $b$ : Faculty of Bioscience Engineering, Université catholique de Louvain, Croix du Sud, 2 bte L7.05.01 B-1348 Louvain-la-Neuve, Belgium, c: Center for Sustainable Development, College of Arts and Sciences, Qatar University P.O. Box 2713, Doha, Qatar, d: Department of Energy Technology, Aalborg University, Niels Bohrs vej 8, DK-6700 Esbjerg, Denmark, e: Group 42 (Healthcare), Capital Gate, Al Khaleej Al Arabi Street Abu Dhabi, United Arab Emirates;

*Corresponding author: iwona.cybulska@uclouvain.be

\section{INTRODUCTION}

Halophytes are salt-tolerant plants and represent a potential green biomass resource in coastal and desert areas. They can tolerate harsh climatic conditions, including high water and soil salinity, high temperatures, and humidity. These plants thrive in conditions that would be lethal to most glycophytes (plants that grow in non-saline conditions), which makes them attractive to researchers (Khan and Qaiser 2006; Flowers and Colmer 2008; Rozema and Flowers 2008). For example, the Persian (Arabian) Gulf region is characterized by higher than average temperatures and seawater salinities, compared to other continental climate regions and bodies of water, respectively. During the summer, the seawater salinity can reach up to $50 \mathrm{PSU}$, which is higher than the normal Indo-Pacific oceanic salinity (about $35 \mathrm{PSU}$ ), while the air temperature can approach $50{ }^{\circ} \mathrm{C}$ (Coles 2003 ; Pain and Abdelfattah 2014). Over 20 species of halophytes grow naturally in the Gulf region (Böer and Saenger 2006). These native species include Arthrocnemum macrostachyum (Moric.) C. Koch, Halocnenum strobilaceum (Pall.) M. Bieb., Halopeplis perfoliata (Forssk.) Schweinf. \& Aschers., Anabasis setifera DC., Salsola rosmarinus (Ehrenb. ex Boiss.), Salsola drummondii Ulbr.; Caroxylon imbricatum (Forssk.) Akhani and E. H. Roalson (Basionym: Salsola imbricata Forssk.), Binertia sinuspersici Akhani, Salicornia sinus-persica Akhani, Suaeda iranshahrii Akhani \& Freitag, Suaeda vermiculata Forssk., Avicennia marina (Forssk.) Vierh., Tetraena (Zygophyllum) qatarensis (Schweinf.) Beier \& Thulin var. qatarensis (Hadidi) Alzahrani \& Albokhari (Brown 2006; Ghazanfar et al. 2014). 
Currently, these previously listed native halophyte species have no particular largescale commercial/economic uses, except for some attempts to use them as fodder for small ruminants (Kraidees et al. 1998). However, halophytes have been historically used in many cultures as medicinal plants (Popp 1984; Rashid 1994; Daoud et al. 2001; Towhidi and Zhandi 2007; Custódio et al. 2012; Ksouri et al. 2012; Rodrigues et al. 2014; Yang et al. 2014). The medicinal properties are attributed to the therapeutic properties of their secondary metabolites, which are mostly present in the extractives fraction of the plant. Secondary metabolites are bioactive compounds, produced by plants, which are generally not directly involved in normal growth and reproduction. These bioactive compounds include protective compounds, which halophytes and other extremophiles produce as a special adaptation against the harsh environmental conditions, e.g., high salinity, which could otherwise cause damage in cell DNA, RNA, and proteins due to the production of reactive oxygen species (ROS) (Singh and Gabani 2011; Flowers and Colmer 2015).

In general, plants have evolved two antioxidative pathways to combat possible cellular damage caused by ROS: an enzymatic pathway, which involves enzymes such as superoxide dismutase and catalase, and a non-enzymatic pathway, which includes antioxidants, such as tocopherol, carotenoids, ascorbate, phenolic compounds, alkaloids, glutathione, and non-protein amino acids that scavenge free radicals (Gill and Tuteja 2010). As an adaptation to stressful environmental conditions, halophytes are more likely to produce higher levels of these enzymes and antioxidants. For example, the review by Bose et al. (2014) presents many studies in which halophytes have exhibited higher antioxidant levels and enzyme activity compared to glycophytes. Similarly, Ellouzi et al. (2011) found that $\alpha$-tocopherol levels were two to five times higher in a halophyte Cakile maritima versus a related glycophyte Arabidopsis thaliana, particularly when exposed to salt concentrations above $10 \mathrm{ppm}$. Additionally, osmolytes, such as glycine betaine and proline, which are produced by halophytes to adjust osmotically to saline conditions, may also provide protection against free radicals (Jithesh et al. 2006).

Due to the extreme stress that the halophytes native to the Gulf region experience, they are likely to be superproducers of protective compounds. Particularly, the antioxidants may have potential commercial applications in the production of high-value nutraceuticals and pharmaceuticals. Cybulska et al. (2014a) reviewed the phytochemical profile of halophytes native to United Arab Emirates (UAE) and found many examples of species with potentially useful extractives. For example, S. vermiculata extract contains phenolic compounds and triterpenoids, which have been shown to prevent cardiovascular diseases (Oueslati et al. 2012). Also, the extract of T. qatarensis has antimicrobial effects (Mahasneh 2002), whereas A. macrostachyum and Salsola spp. contain flavonoids and phenols with antioxidant and anti-inflammatory properties (Custódio et al. 2012; Abdou et al. 2013; Akbar and Yahya 2011). Several species of the family Zygophyllaceae are Middle-Eastern halophytes that have been previously studied for their phytochemical potential (Amin et al. 2010, 2011; Hussein et al. 2011). From the extractive fractions of Tetraena alba and Zygophyllum gaetulum species, essential oils and bioactive compounds were isolated (Jaouhari et al. 2000; Tigrine-Kordjani et al. 2006; Tigrine-Kordjani et al. 2011).

Biofuels have a key role in green transition and decreasing greenhouse gas emissions to the atmosphere. However, the use of first generation feedstocks, such as starch and edible oils, is considered unsustainable due to high competition with food resources. A biorefinery from second generation feedstocks targeting only the production of biofuels is rarely economically profitable, but introducing value-added products to the process would improve the feasibility (Severo et al. 2019). Besides extractive fractions, halophytes 
have lignocellulose structure (with some compositional differences), which can be used as a feedstock for production of second-generation biofuels. Therefore, the extractives could potentially be used for the productions of some high-value compounds, and the leftover fraction used for the production of biofuels. As halophyte extracts have shown antimicrobial, anti-inflammatory, and even cytotoxic properties (Ksouri et al. 2021; Omaruyi et al. 2021; Rashid 1994; Rodrigues et al. 2014), they would potentially provide a bio-based alternative to some petroleum-based antibiotics and cancer drugs, which are also sourced from over-exploited oil reservoirs.

Considering these aspects, halophyte biomass may present an avenue for local biofuel production in the Middle East (Flowers and Colmer 2008; Brown et al. 2014; Cybulska et al. 2014c), as traditional second-generation lignocellulosic feedstocks, including cereal straws and agricultural residues, are scarce in the arid regions or cannot be produced sustainably. Furthermore, as halophytes can thrive on lower quality (saline or nutrient-lacking) soils using saline water for irrigation, cultivation of these plants would reduce the need for fertile soil and freshwater irrigation. This would also further reduce the competition with food production. Besides advantages in the cultivation phase, preliminary studies (Cybulska et al. 2014c) show that milder process conditions are required to pretreat halophyte straw (severity factor < 4.0) compared to the processing of commonly used feedstocks. This means pretreatment in lower temperatures or with shorter retention time (Brudecki et al. 2012; Cybulska et al. 2013). Thus, halophytes could be considered as an alternative for the traditional second-generation feedstocks.

In this work, an assessment was carried out of the compositional differences among a variety of halophyte species native to the Gulf region, collected in the summer along the coastal areas of Abu Dhabi, UAE. The samples of Arthrocnenum macrostachyum, Bienertia sinuspersici, Caroxylon imbricatum, Salsola drummondii, Halopeplis perfoliata, Suaeda vermiculata, Cornulaca aucheri, Tetraena (Zygophyllum) qatarensis, Tetraena aff coccinea (Zygophyllum aff. coccineum), and Salicornia sinus-persica were characterized in order to evaluate their suitability for biorefinery applications. All characterized plant species are members of Chenopodioideae and most of them belong to the Amaranthaceae family, excluding two Tetraena (Zygophyllum) species belonging to the Zygophyllaceae family. Amounts of lignocellulose compounds were analyzed, in an aim to find alternative raw materials for possible biofuel production, and the amount of extractive material was determined, as it could be valorized as value-added products.

\section{EXPERIMENTAL}

\section{Sample Collection and Pretreatment}

Plant samples of A. macrostachyum (AM), B. sinuspersici (BS), C. imbricatum (CI), S. drummondii (SD), H. perfoliata (HP), S. vermiculata (SV), C. aucheri (CA), $T$. qatarensis (TQ), T. aff coccinea (TC) and S. sinus-persica (SS) were collected on 8 July 2014 from a coastal site in the Western region of Abu Dhabi (52.554 N 24.129 E). This region (also known as the Al Dhafra Region or Al Gharbia in Arabic) is located between the areas of Al Hamra and Al Ruwais. After collection, samples were air-dried and milled to achieve $\leq 1 \mathrm{~mm}$ particle size using laboratory-scale knife mill (IKA, $10 \mathrm{MF}$ Basic).

\section{Chemical Analysis}

Standard procedures of lignocellulosic biomass characterization were employed (based on NREL protocols listed in the following sections). First, the amount of extractive 
material in plant biomass was determined. Subsequently, the content of lignocellulose compounds (carbohydrates and lignin) was analyzed. Extractable and structural ash content were measured in order to determine the feasibility of extractive-ash removal by a freshwater wash.

\section{Determination of water- and ethanol-soluble extractives}

Three quantities were measured during this analysis: water-soluble extractives, ethanol-soluble extractives, and total extractives, which is the summation of two previously mentioned fractions. Amounts of extractives were determined by measuring the content of dissolved solids from the obtained extracts. Total extractives were also determined as a weight loss of extracted solid sample (Sluiter et al. 2008c).

Dried and milled sample ( $3 \mathrm{~g})$ was placed in an alundum thimble and extracted in sequence with water and ethanol (100 g) using a Soxhlet apparatus. Both extractions were run for $12 \mathrm{~h}$ ( 3 to 4 and 5 to 6 cycles per hour for water and ethanol, respectively). The extractive-free material was removed from the thimble and oven-dried overnight at $105{ }^{\circ} \mathrm{C}$ to determine total (including volatile and non-volatile) extractives (Eq. 1).

Non-volatile water- and ethanol-soluble extractives were measured as solids content in the extracts (by evaporating the solvent in a vacuum oven and weighing the solid residue), and their amounts were calculated using Eq. 2,

$$
T E=\frac{T S-W_{\text {dried extracted biomass }}}{T S} * 100
$$

where $T E$ is total extractives (g/100gTS), TS is total solids of the original biomass ( $\mathrm{g}$ ), and $W$ dried extracted biomass is the weight of the extractive-free biomass removed from the thimble and dried $(\mathrm{g})$,

$N E=\frac{W_{\text {dried water or ethanol extract }}}{T S} * 100$

where $N E$ is non-volatile extractives $(\mathrm{g} / 100 \mathrm{gTS})$, and $W_{\text {dried }}$ water or ethanol extract is weight of the dried ethanol extract $(\mathrm{g})$.

\section{Determination of Lignocellulosic Components (carbohydrates and lignin)}

Extractive-free biomass was analyzed for carbohydrates and lignin content via strong acid hydrolysis, following NREL standard protocol (Sluiter et al. 2008b). The dried extractives-free sample $(0.3 \mathrm{~g})$ was digested in sealed pressure tubes with $3.00 \mathrm{~mL}$ of $72 \%$ sulfuric acid for $1 \mathrm{~h}$, after which the reaction was quenched by adding $84 \mathrm{~mL}$ deionized water to achieve $4 \%$ solution of the sulfuric acid. The tubes were placed in an autoclave at $121^{\circ} \mathrm{C}$ for $1 \mathrm{~h}$ to complete the digestion. After cooling, the hydrolysate was filtered through a fritted ceramic funnel, and the filtrate was analyzed for free sugars (glucose, xylose and arabinose) and organic acids (acetic, lactic and formic acids) using High Performance Liquid Chromatography (Agilent 1260 Infinity Bio-inert Binary LC). The Hi Plex-H column (Agilent) and refractive index detector (RID) were used to determine the concentrations of glucose, xylose, and arabinose at $65{ }^{\circ} \mathrm{C}$ using $0.005 \mathrm{M} \mathrm{H}_{2} \mathrm{SO}_{4}$ as the mobile phase (eluent) with a flow rate of $0.6 \mathrm{~mL} / \mathrm{min}$. Carbohydrate content in the extractive-free biomass was calculated as presented by Eq. 3,

$$
\text { Sugar }_{\text {extractives-free }}=\frac{C_{\text {anhydro }} * V_{\text {hydrolysate }} * \frac{1 \mathrm{~g}}{1000 \mathrm{mg}}}{T S_{\text {extractives }} \text {-free }} * 100
$$

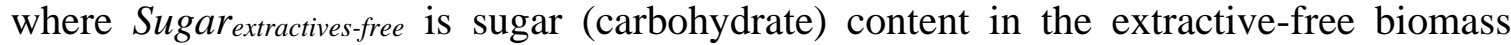
(g/100gTS), $C_{\text {anhydro }}$ is concentration of a measured sugar converted to its polymeric form, 
additionally corrected for degradation during the dilute-acid step of the hydrolysis (using a recovery factor measured by spiking sample replicates with a standard) (g/L), Vhydrolysate is the volume of the hydrolyzate $(\mathrm{mL})$, and $T S_{\text {extractives-free }}$ is the extractive-free total solids content $(\mathrm{g})$.

The carbohydrate content in the extractive-free biomass does not reflect its content in the original plant; thus the carbohydrate content on the "as received" basis was additionally calculated to reflect the original plant composition (Eq. 4).

Sugar $r_{\text {as received }}=$ Sugar $_{\text {extractives }- \text { free }} * \frac{(100-\text { extracts })}{100}$

Klason lignin (acid insoluble lignin) was calculated based on the weight measurement of the dry residue remaining after the acid digestion corrected for ash (Eq. 5). Lignin content in the original plant was then calculated following the principle of Eq. 4 ,

$A I L_{\text {extractives-free }}=\frac{\left(W_{\text {AIL }}-W_{\text {ash }}\right)}{T S_{\text {extractives }} \text { free }} * 100 \%$

where AIL extractives-free is acid insoluble lignin (g/100gTS), $W_{A I L}$ is the weight of acid insoluble lignin after drying at $105^{\circ} \mathrm{C}(\mathrm{g})$ and $W_{\text {ash }}$ is the weight of the residue after baking at $575{ }^{\circ} \mathrm{C}(\mathrm{g})$.

\section{Determination of ash (structural, extractable and total)}

Total ash (TA) was measured in the original plant following the NREL protocol (Sluiter et al. 2008a) (Eq. 6). Extractable ash (EA) was analyzed by measuring the total solids and then ash content in the water extracts, and then relating it to the dry matter raw sample (Eq. 7). Ash content measured in the extractive-free material (after extractable ash removal) was characterized as structural ash (SA) (Eq. 8).

$$
T A=\frac{A W R}{T S} * 100 \%
$$

where $T A$ is total ash content $(\mathrm{g} / 100 \mathrm{gTS})$ and $A W R$ is ash weight in the raw biomass $(\mathrm{g})$.

$$
E A=\frac{A W E}{T S} * 100 \%
$$

where $E A$ is extractable ash $(\mathrm{g} / 100 \mathrm{gTS})$ and $A W E$ is ash weight in the extract $(\mathrm{g})$.

$$
S A=\frac{A W E F}{T S} * 100 \%
$$

In Eq. 8, $S A$ is structural ash (g/100gTS) and $A W E F$ is ash weight in the extractive-free biomass $(\mathrm{g})$.

\section{Statistical Analysis}

Statistical mean comparison and testing for significance of differences were performed using Tukey's Honestly Significant Difference (HSD) (Eq. 9), as it allows comparisons among multiple means and it is relatively conservative. All the characterization analyses were performed in duplicates $(n=2)$.

$$
\mathrm{HSD}=q \sqrt{\frac{M S E}{n}}
$$


where HSD is Tukey's Honestly Significant Difference, q is the critical value from studentized range table for $\mathrm{p}<.05, M S E$ is mean square of error, and $n$ is the number of replicates per treatment.

Two hypotheses were tested: $\mathrm{H}_{\mathrm{o}}: \mu_{\mathrm{i}}=\mu_{\mathrm{j}}$ and $\mathrm{H}_{\mathrm{a}}: \mu_{\mathrm{i}} \neq \mu_{\mathrm{j}}$ (i and $\mathrm{j}$ represent different populations, i.e. different halophyte species). The null hypothesis $\left(\mathrm{H}_{\mathrm{o}}\right)$ was rejected when $\left|\bar{X}_{l}-\bar{X}_{J}\right|>$ HSD.

\section{RESULTS AND DISCUSSION}

\section{Determination of Water- and Ethanol-soluble Extractives}

In general, little or no differences were observed among the species in terms of ashfree extractives content. There was no significant difference in the amounts of ethanolsoluble material between any of the studied plant species. For the water-soluble material, the differences were found to be significantly different only between $T$. qatarensis (17.08 $\mathrm{g} / 100 \mathrm{gDM})$, C. aucheri (12.79 g/100gDM), and S. sinus-persica $(10.17 \mathrm{~g} / 100 \mathrm{gDM})$. For other plant species, there was no significant difference in the content of water-soluble extractives.

Even after removal of the extractable ash, the extracted fraction can still be considered high, constituting between 17 to $30 \%$ of the dry matter content, depending on the species (Fig. 1). Water extractives were found to represent the majority of the total extractives value for all the plants, except for $S$. sinus-persica, which showed similar contents for both water- and ethanol-soluble extractives. In S. sinus-persica, the amount of ethanol-soluble material $(8.82 \mathrm{~g} / 100 \mathrm{gDM})$ is nearly double compared to the species with the second highest content of ethanol extractives (4.48 g/100gDM in H. perfoliata).

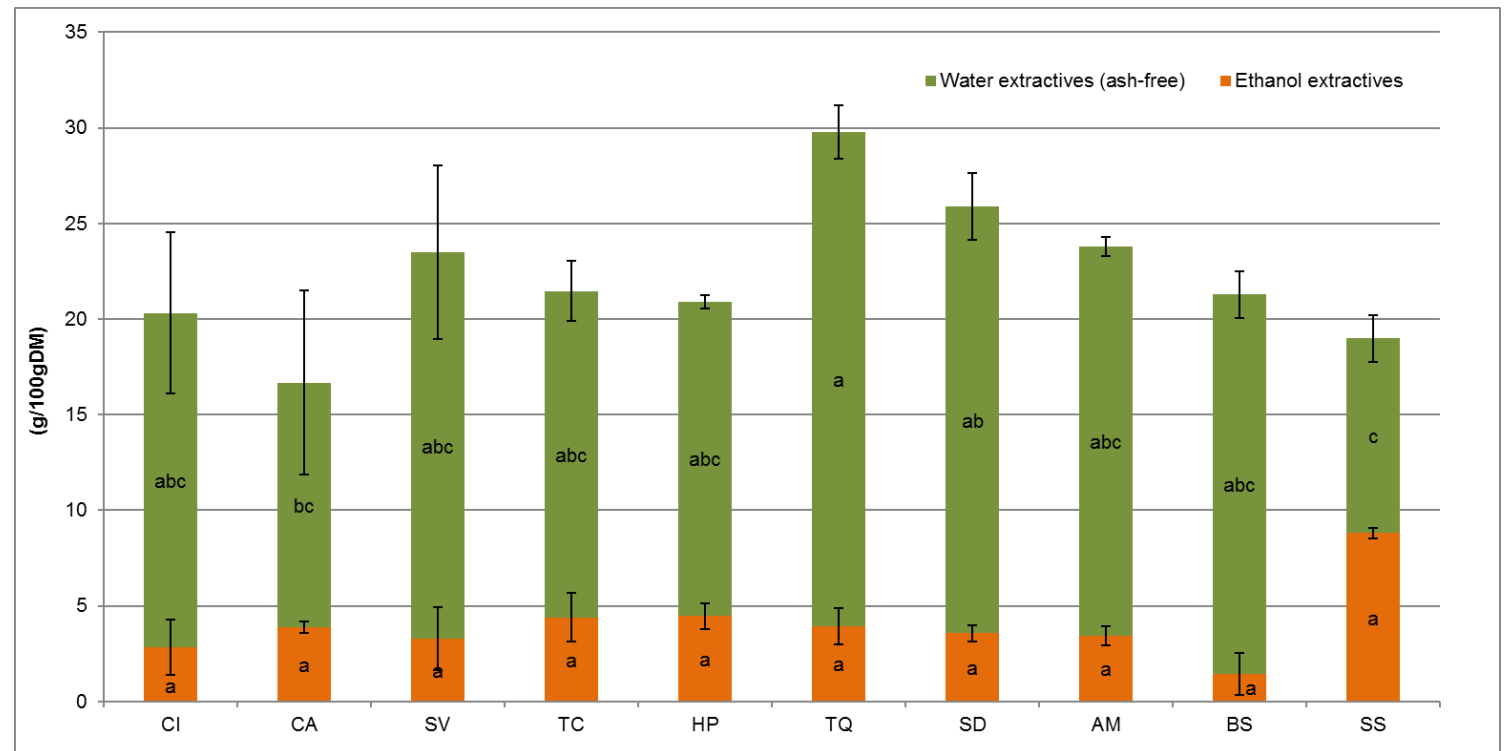

Fig. 1. Total cumulative amount of extractive material in the dry matter of analyzed halophyte species. Different letters denote statistically significant differences $(p<.05)$ among the mean values, determined individually for each analyzed component. CI: C. imbricatum, CA: C. aucheri, SV: S. vermiculata, TC: T. aff coccinea, HP: H. perfoliata, TQ: T. qatarensis, SD: S. drummondii, AM: A. macrostachyum, BS: B. sinuspersici, and SS: S. sinus-persica. 
Previous studies revealed that using water or hydroalcoholic extraction solvents considerably influenced the extraction capacity of bioactive compounds from halophytic and non-halophytic plants in a positive way (Chavan et al. 2001; Trabelsi et al. 2010; Omoruyi et al. 2012). Thus, alternative solvents could be considered when targeting the production of bioactive botanical extracts. The large fraction of extractive material in the biomass could indicate high concentrations of high-value bioactive compounds in the plant. Such plants would be desirable for biorefinery, as value-added products could increase the feasibility of the process. However, a further examination of the detailed composition of botanical extracts would be needed in order to know the amount of different secondary metabolites in them and plan targeted compound and possible processing routes.

\section{Determination of Lignocellulosic Components (carbohydrates and lignin)}

All the species analyzed were found to contain the typical lignocellulosic components: extractives, carbohydrates, lignin, and ash (Fig. 2). The highest carbohydrate (total sugar) contents were found for C. aucheri $(34.25 \mathrm{~g} / 100 \mathrm{gDM})$ and $S$. sinus-persica, $(33.43 \mathrm{~g} / 100 \mathrm{gDM})$, suggesting these species to be the most attractive for possible alternative biofuel feedstock after extraction, as the hydrolyzed sugars will be consumed by micro-organisms in processing of biofuels, such as biogas or bioethanol. The lignin content was also found to be relatively low for most of the species $(<20 \mathrm{~g} / 100 \mathrm{gDM})$, making the plant biomass possibly more amenable for processing, as the recalcitrance of the biomass decreases with decreasing content of this protective polymer. Thus, less severe pretreatment conditions would also prevent the production of degradation products, such as furfural and hydroxymethylfurfural, which could be inhibitory for enzymatic hydrolysis or fermentation (Arora et al. 2012; Ran et al. 2014).

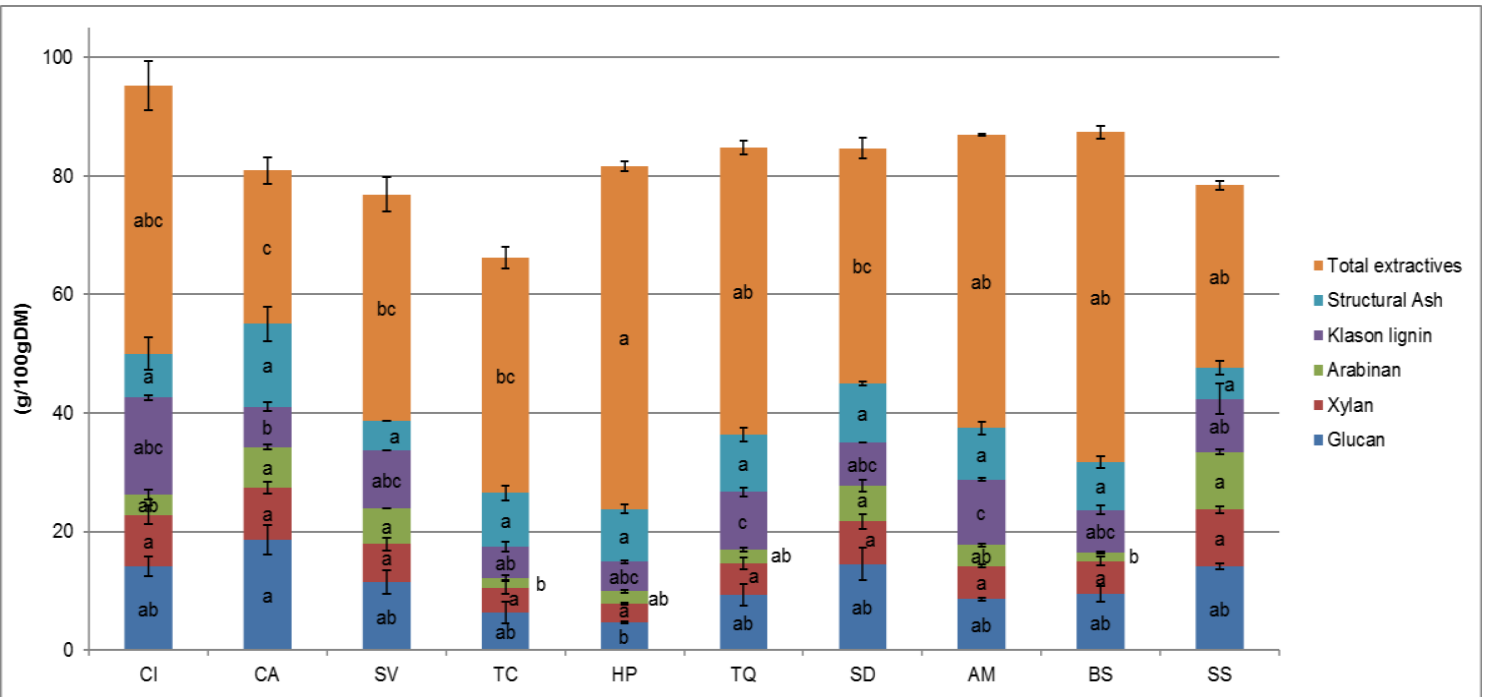

Fig. 2. Content of lignocellulosic components in the dry matter of analyzed halophyte species. Different letters denote statistically significant differences $(p<.05)$ among the mean values, determined individually for each analyzed component. $\mathrm{Cl}$ : $C$. imbricatum, CA: $C$. aucheri, SV: $S$. vermiculata, TC: T. aff coccinea, HP: H. perfoliata, TQ: T. qatarensis, SD: S. drummondii, AM: $A$. macrostachyum, BS: B. sinuspersici, and SS: S. sinus-persica.

Some significant $(\mathrm{p}<.05)$ species-specific differences were observed for concentrations of glucan, lignin, and total extractives. $C$. aucheri contains significantly lower amount of extractives $(25.88 \mathrm{~g} / 100 \mathrm{gDM})$ compared to $H$. perfoliata, T. qatarensis, A. macrostachyum, B. sinuspersici and $S$. sinus-persica. On the other hand, the fraction of total extractive material in $H$. perfoliata $(57.81 \mathrm{~g} / 100 \mathrm{gDM})$ was found to be significantly 
larger than in $C$. aucheri, $T$. aff coccieneum, S. vermiculata, and S. drummondii. Considering the Klason lignin content, $T$. qatarensis $(21.42 \mathrm{~g} / 100 \mathrm{gDM})$ and $A$. macrostachyum (23.85 g/100 gDM) were observed to contain significantly higher lignin content than other species, and these were the only species with a lignin content above 20 $\mathrm{g} / 100 \mathrm{gDM}$. C. aucheri contain significantly lower amount of lignin $(6.80 \mathrm{~g} / 100 \mathrm{gDM})$ compared to T. qatarensis and A. macrostachyum. C. aucheri also exhibited higher glucan content than any of the other studied species $(18.60 \mathrm{~g} / 100 \mathrm{gDM})$. No significant differences were found in the xylan content of plants.

C. aucheri, as well as previously studied species native to the Gulf, have reported to contain high level of carbohydrates content (nitrogen-free extract), and the content was found to increase during dry periods (Morsy et al. 2008; Shaltout et al. 2008; Gad et al. 2012). However, when compared to other lignocellulosic biomasses, such as prairie grasses or corn stover (Cybulska et al. 2012), the glucan fraction of halophytes was found to be relatively low $(<20 \mathrm{~g} / 100 \mathrm{gDM})$ and the total extractives fraction relatively high $(>30$ $\mathrm{g} / 100 \mathrm{gDM})$, as it contained the extractable ash washed out from the salty plants.

\section{Determination of Ash (structural, extractable, and total)}

For the studied halophyte species, Fig. 3 illustrates the ash distribution in the samples, showing the efficiency of the salt removal by water wash in form of the extractable ash value.

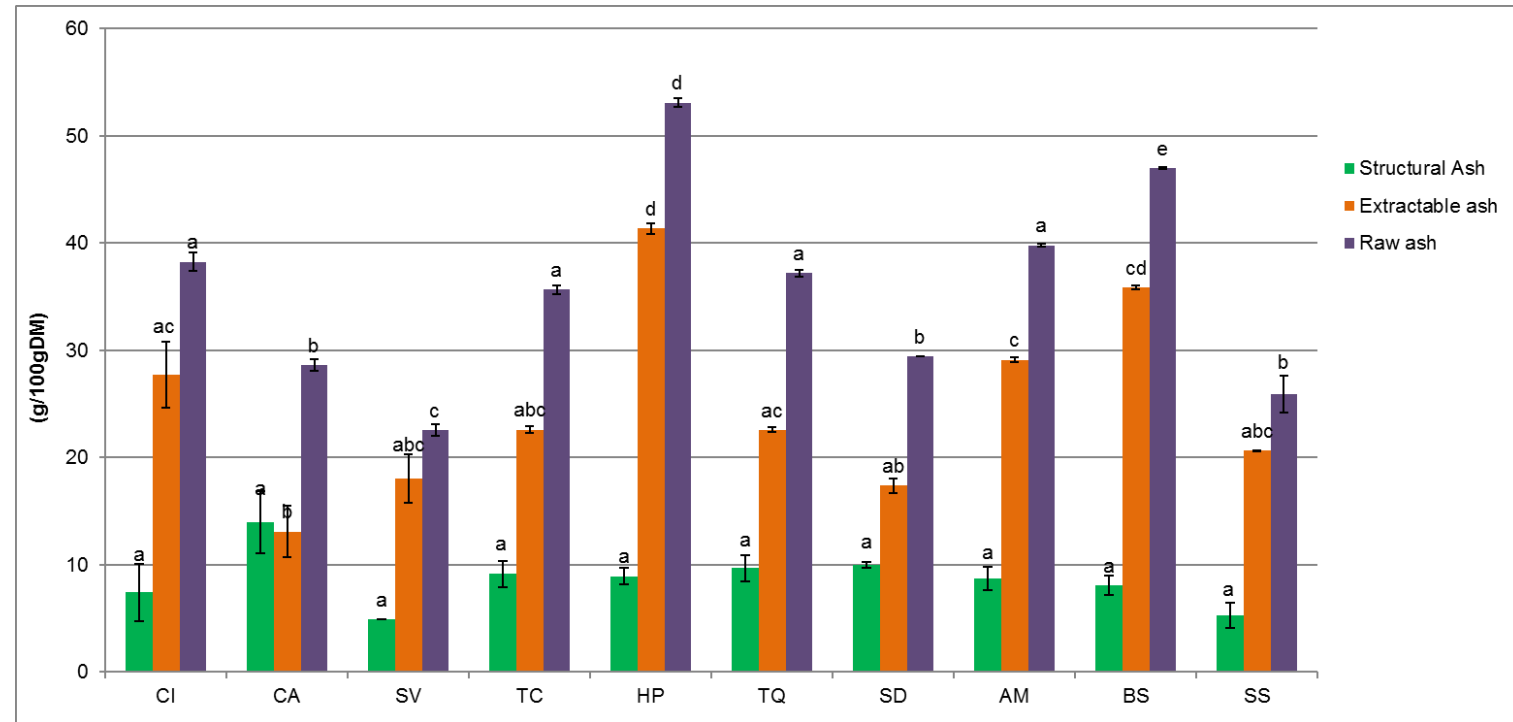

Fig. 3. Ash distribution in the dry matter of analyzed halophyte species. Different letters denote statistically significant differences $(p<.05)$ among the mean values, determined individually for each analyzed component. Cl: $C$. imbricatum, CA: $C$. aucheri, SV: S. vermiculata, TC: T. aff coccinea, HP: H. perfoliata, TQ: T. qatarensis, SD: S. drummondii, AM: A. macrostachyum, BS: $B$. sinuspersici, and SS: S. sinus-persica.

Extractable ash represents 45 to $80 \%$ of the total ash measured in the raw plant depending on the species. Significant differences in total (raw) and extractable ash content have been observed among the species. The amount of extractive ash was lowest in $C$. aucheri $(13.10 \mathrm{~g} / 100 \mathrm{gDM})$ and highest in B. sinuspersici $(35.88 \mathrm{~g} / 100 \mathrm{gDM})$. H. perfoliata and $B$. sinuspersici were found to contain the highest amount of total ash $(54 \mathrm{~g} / 100 \mathrm{gDM}$ and $47 \mathrm{~g} / 100 \mathrm{gDM}$, respectively), and $S$. vermiculata contained the lowest amount of total ash (23 g/100gDM). C. imbricatum, T. aff coccinea, T. qatarensis, and A. macrostachyum 
were in the group containing medium amounts (30 to $40 \mathrm{~g} / 100 \mathrm{gDM}$ ) of total ash. No significant differences were found in the content of structural ash in the plant biomass.

\section{Influence of Ash}

Raw ash content in the plant was found to influence plant composition to an extent, as there was a correlation between ash and the amounts of some structural components in the species analyzed. Carbohydrate content in the plants was negatively correlated with ash content, the correlation being similar for both glucan and xylan (two most abundant carbohydrates in the lignocellulosic plants) with $\mathrm{R}^{2}$ of -0.67 for each (Fig. $4 \mathrm{~A}$ and $4 \mathrm{~B}$ ). No clear correlation was observed between the raw ash concentration and the content of ashfree extractive material and lignin, $\mathrm{R}^{2}$ values being -0.35 and 0.34 , respectively (data not shown).
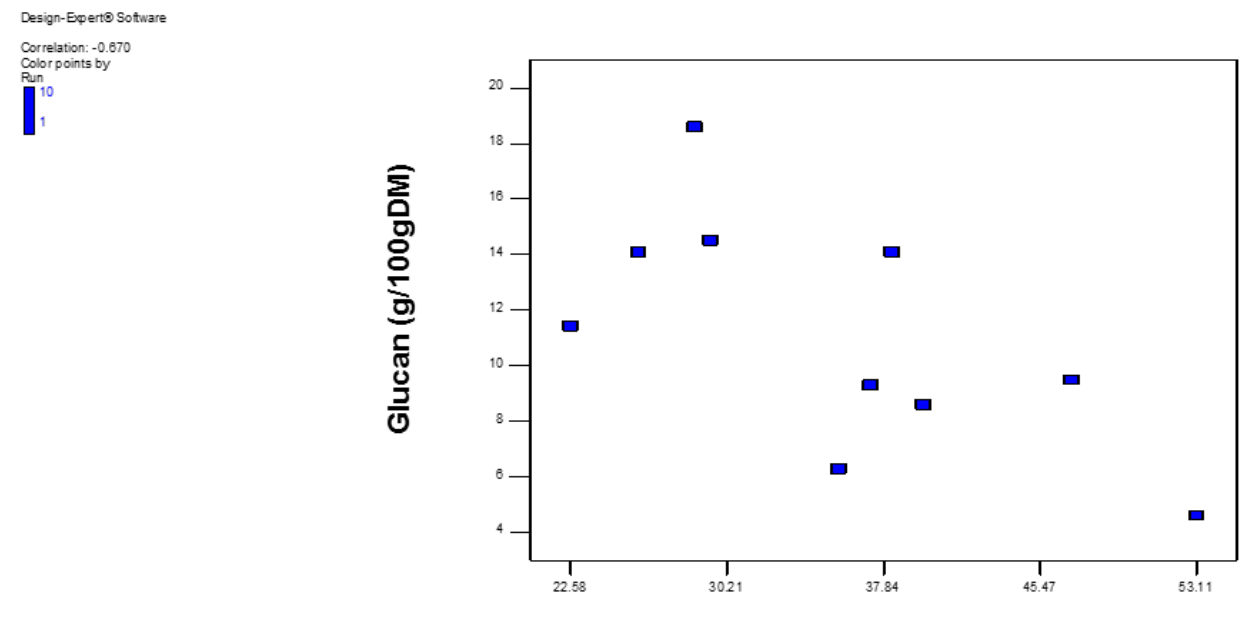

A: Raw plant ash (g/100gDM)
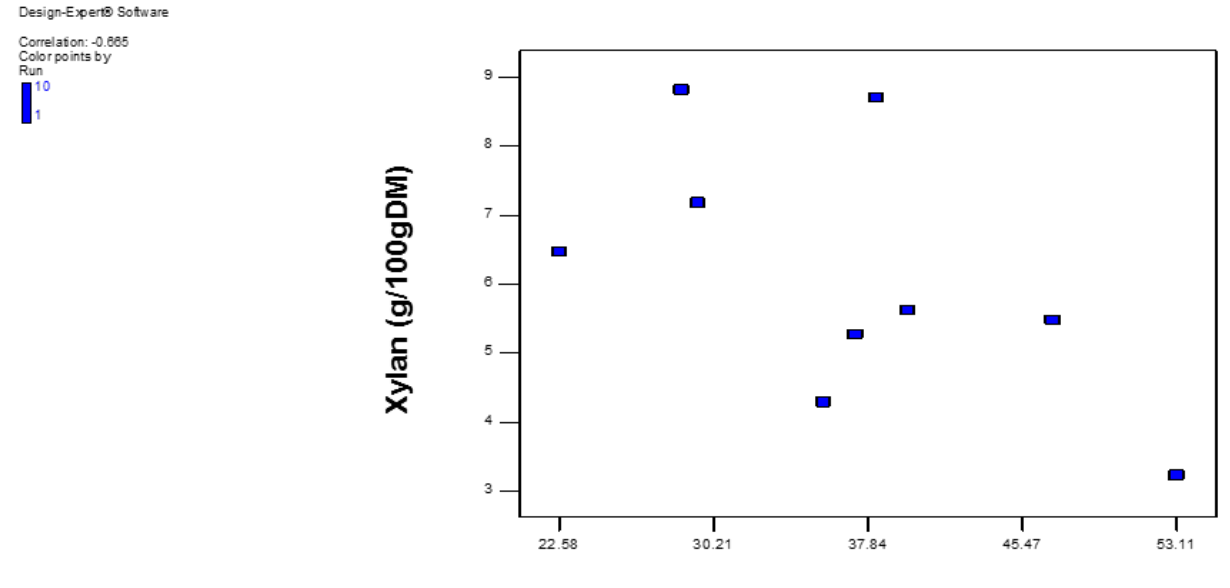

A: Raw plant ash (g/100gDM)

Fig. 4. Correlation between glucan (A) and xylan (B) content of halophyte biomass and the content of raw ash in examined halophyte samples

As the analyzed plant samples were collected from the same area, differences in the growing conditions may not influence the raw ash content. However, the observed differences among the species may be due to different salt uptake mechanisms of the plant species. Previous studies showed no correlation between structural ash content of saltbushes and soil salinity (Beadle et al. 1957; Welch 1978), whereas increasing the 
salinity of nutrient solution increased the total ash content of the plant (Beadle et al. 1957). The differences in the raw ash content of plants were found to be significant in the present study (Fig. 3). Thus, the differences in the carbohydrate content among the analyzed halophyte species, being related to the raw ash content, are most probably caused by the different rates of salt uptake and retention mechanisms varying from species to species. The negative influence of ash on the carbohydrate content was also observed in a cultivation study of Salicornia bigelovii, where the relationship between plant ash content was and the irrigation water salinity and amount of nitrogen in the fertilizer during cultivation was examined (Cybulska et al. 2014b). Also, a decrease in soil salinity was reported to increase the carbohydrate content in the plant structure of in other halophytes, including three different Salsola species (Heidari-Sharifabad and Mirzaie-Nodoushan 2006).

\section{CONCLUSIONS}

1. It was found that the analyzed species contain significantly different amounts of carbohydrates, lignin, extractable ash, and ash-free water-soluble extractives.

2. Total ash content was found to negatively influence the content of glucan and xylan in the biomass $\left(\mathrm{R}^{2}=-0.67\right)$. No correlation was seen between the total ash content and the content of the ash-free extractive material and lignin.

3. Cornulaca aucheri was found to have relative low lignin content and the highest glucan content of all characterized halophytes, whereas Tetraena qatarensis was found to contain the highest amount of the ash-free extractives.

4. Cornulaca aucheri would be the most promising feedstock for lignocellulose-based biorefinery processing, targeting the production of second-generation biofuels, and Tetraena qatarensis would be the best substrate for generating extractives-based products, as the extract from this species has reported to contains various bioactive compounds (Cybulska et al. 2014a).

\section{ACKNOWLEDGMENTS}

This work was funded by Masdar Institute of Science and Technology (Masdar Institute), Abu Dhabi, UAE.

\section{REFERENCES CITED}

Abdou, A. M., Abdallah, H. M., Mohamed, M. A., Fawzy, G. A., and Abdel-Naim, A. B. (2013). "A new anti-inflammatory triterpene saponin isolated from Anabasis setifera," Arch. Pharm. Res. 36(6), 715-722.

Akbar, S., and Yahya, A. (2011). "Screening of Saudi plants for phytoconstituents, pharmacological and antimicrobial properties," Austr. J. Med. Herbal. 23(2), 76-87.

Amin, E., El-Hawary, S., Fathy, M., Mohammed, R., Ali, Z., and Khan, I. (2010). "Zygophylloside $S$, a new triterpenoid saponin from the aerial parts of Zygophyllum coccineum L." Planta Med., 76(05), P51. DOI: 10.1055/s-0030-1251813. 
Amin, E., El-Hawary, S. S., Fathy, M. M., Mohammed, R., Ali, Z., Tabanca, N., Wedge, D. E., Becnel, J. J., and Khan, I. A. (2011). "Triterpenoidal saponins: Bioactive secondary metabolites from Zygophyllum coccineum," DTIC Document.

Arora, A., Martin, E. M., Pelkki, M. H., and Carrier, D. H. (2012). "Effect of formic acid and furfural on the enzymatic hydrolysis of cellulose powder and dilute acidpretreated poplar hydrolysates," ACS Sustainable Chem. Eng. 1(1), 23-28. DOI: $10.1021 / \mathrm{sc} 3000702$.

Beadle, N., Whalley, R., and Gibson, J. (1957). "Studies in halophytes: II. Analytic data on the mineral constituents of three species of atriplex and their accompanying soils in Australia," Ecology 340-344. DOI: 10.2307/1931694.

Böer, B., and Saenger, P. (2006). "The biogeography of the coastal vegetation of the Abu Dhabi gulf Coast," Sabkha Ecosystems 2006, 31-36. DOI: 10.1007/978-1-4020-50725_3.

Brown, G. (2006). "The sabkha vegetation of the United Arab Emirates," in: Sabkha Ecosystems, Springer, pp. 37-51. DOI: 10.1007/978-1-4020-5072-5_4.

Brown J.J., Cybulska I., Chaturvedi T., and Thomsen M.H. (2014). "Halophytes for the Production of Liquid Biofuels," in: Khan M.A., Böer B., Öztürk M., Al Abdessalaam T.Z., Clüsener-Godt M., Gul B. (eds) in: Sabkha Ecosystems. Tasks for Vegetation Science, Springer, vol 47, pp. 67-72. DOI: 10.1007/978-94-007-7411-7.Brudecki, G., Cybulska, I., Rosentrater, K., and Julson, J. (2012). "Optimization of clean fractionation processing as a pre-treatment technology for prairie cordgrass." Bioresour. Technol. 107, 494-504. DOI: 10.1016/j.biortech.2011.12.122.

Chavan, U., Shahidi, F., and Naczk, M. (2001). "Extraction of condensed tannins from beach pea (Lathyrus maritimus L.) as affected by different solvents," Food Chem. 75(4), 509-512. DOI: 10.1016/S0308-8146(01)00234-5.

Coles, S. L. (2003). Coral Species Diversity and Environmental Factors in the Arabian Gulf and the Gulf of Oman: A Comparison to the Indo-Pacific Region, National Museum of Natural History, Smithsonian Institution.

Custódio, L., Ferreira, A. C., Pereira, H., Silvestre, L., Vizetto-Duarte, C., Barreira, L., Rauter, A. P., Alberício, F., and Varela, J. (2012). "The marine halophytes Carpobrotus edulis L. and Arthrocnemum macrostachyum L. are potential sources of nutritionally important PUFAs and metabolites with antioxidant, metal chelating and anticholinesterase inhibitory activities," Bot. Mar. 55(3), 281-288. DOI: 10.1515/bot2012-0098.

Cybulska, I., Brudecki, G., Rosentrater, K., Julson, J. L., and Lei, H. (2012). "Comparative study of organosolv lignin extracted from prairie cordgrass, switchgrass and corn stover," Bioresour. Technol. 118, 30-36. DOI: 10.1016/j.biortech.2012.05.073.

Cybulska, I., Brudecki, G., and Lei, H. (2013). "Hydrothermal pretreatment of lignocellulosic biomass," in: Green Biomass Pretreatment for Biofuels Production, Springer, 87-106. DOI: 10.1007/978-94-007-6052-3_4.

Cybulska, I., Brudecki, G., Alassali, A., Thomsen, M., and Brown, J. J. (2014a). "Phytochemical composition of some common coastal halophytes of the United Arab Emirates," Emir. J. Food Agricult. 26(12). DOI: 10.9755/ejfa. v26i12. 19104. DOI: 10.9755/ejfa.v26i12.19104.

Cybulska, I., Chaturvedi, T., Alassali, A., Brudecki, G. P., Brown, J. J., Sgouridis, S., and Thomsen, M. H. (2014b). "Characterization of the chemical composition of the halophyte Salicornia bigelovii under cultivation," Energ. Fuel. 28(6), 3873-3883. DOI: 10.1021/ef500478b. 
Cybulska, I., Chaturvedi, T., Brudecki, G. P., Kádár, Z., Meyer, A. S., Baldwin, R. M., and Thomsen, M. H. (2014c). "Chemical characterization and hydrothermal pretreatment of Salicornia bigelovii straw for enhanced enzymatic hydrolysis and bioethanol potential." Bioresour. Technol. 153, 165-172. DOI:

10.1016/j.biortech.2013.11.071.

Daoud, S., Harrouni, M., and Bengueddour, R. (2001). "Biomass production and ion composition of some halophytes irrigated with different seawater dilutions," First International conference on saltwater intrusion and coastal aquifers-monitoring, modeling and management. Essaouira, Morocco, April, 23-25.

Ellouzi, H., Hamed, K. B., Cela, J., Munné-Bosch, S., and Abdelly, C. (2011). "Early effects of salt stress on the physiological and oxidative status of Cakile maritima (halophyte) and Arabidopsis thaliana (glycophyte)." Physiologia Plantarum 142, 128-143. DOI: 10.1111/j.1399-3054.2011.01450.x.

Flowers, T. J., and Colmer, T. D. (2008). "Salinity tolerance in halophytes," New Phytol. 179(4), 945-963. DOI: 10.1111/j.1469-8137.2008.02531.x.

Flowers, T. J., and Colmer, T. D. (2015). "Plant salt tolerance: Adaptations in halophytes," Ann. Bot. 115(3), 327-331. DOI: 10.1093/aob/mcu267.

Gad, M. R. M., El-Hadidy, M. E., and El-Nabarawy, A. A. (2012). "Comparative study on the adaptation of some natural plants grown under macronutrients limitation at North Sinai sand dunes (Egypt)," Ann. Agriult. Sci. 57(1), 81-90. DOI: 10.1016/j.aoas.2012.03.001.

Ghazanfar, S. A., Altundag, E., Yaprak, A. E., Osborne, J., Tug, G. N., and Vural, M. (2014). "Halophytes of Southwest Asia," Sabkha Ecosystems: Volume IV: Cash Crop Halophyte and Biodiversity Conservation, Springer, 105-133. DOI: 10.1007/978-94007-7411-7.

Gill, S. S., and Tuteja, N. (2010). "Reactive oxygen species and antioxidant machinery in abiotic stress tolerance in crop plants," Plant Physiol. Biochem. 48(12), 909-930. DOI: 10.1016/j.plaphy.2010.08.016.

Heidari-Sharifabad, H., and Mirzaie-Nodoushan, H. (2006). "Salinity-induced growth and some metabolic changes in three Salsola species," J. Arid Environ. 67(4), 715720. DOI: 10.1016/j.jaridenv.2006.03.018.

Hussein, S. R., Marzouk, M. M., Ibrahim, L. F., Kawashty, S. A., and Saleh, N. A. (2011). "Flavonoids of Zygophyllum album Lf and Zygophyllum simplex L. (Zygophyllaceae)." Biochem. Syst. Ecol., 39(4), 778-780. DOI: 10.1016/j.bse.2011.07.009.

Jaouhari, J., Lazrek, H., and Jana, M. (2000). "The hypoglycemic activity of Zygophyllum gaetulum extracts in alloxan-induced hyperglycemic rats." J. Ethnopharmacol. 69(1), 17-20. DOI: 10.1016/S0378-8741(99)00064-1.

Jithesh, M., Prashanth, S., Sivaprakash, K., and Parida, A. K. (2006). "Antioxidative response mechanisms in halophytes: their role in stress defence," J. Genet. 85(3), 237-254. DOI: $10.1007 / \mathrm{BF} 02935340$.

Khan, M. A., and Qaiser, M. (2006). "Halophytes of Pakistan: Characteristics, distribution and potential economic usages," in: Sabkha Ecosystems, Springer, pp. 129-153. DOI: 10.1007/978-1-4020-5072-5_11.

Kraidees, M. S., Abouheif, M. A., Al-Saiady, M. Y., Tag-Eldin, A., and Metwally, H. (1998). "The effect of dietary inclusion of halophyte Salicornia bigelovii Torr on growth performance and carcass characteristics of lambs," Anim. Feed Sci. Tech. 76(1-2), 149-159. DOI: 10.1016/S0377-8401(98)00191-6. 
Ksouri, R., Ksouri, W. M., Jallali, I., Debez, A., Magné, C., Hiroko, I., and Abdelly, C. (2012). "Medicinal halophytes: Potent source of health promoting biomolecules with medical, nutraceutical and food applications," Crit. Rev. Biotechnol. 32(4), 289-326. DOI: $10.3109 / 07388551.2011 .630647$.

Mahasneh, A. S. (2002). "Screening of some indigenous Qatari medicinal plants for antimicrobial activity," Phytotherapy Reseach 16(8), 751-753. DOI: 10.1002/ptr.1037

Morsy, A., Youssef, A., Mosallam, H., and Hashem, A. (2008). "Assessment of selected species along Al-Alamein-Alexandria International desert road, Egypt," J. Appl. Sci. Res. 4(10), 1276-1284.

Omoruyi, B. E., Bradley, G., and Afolayan, A. J. (2012). "Antioxidant and phytochemical properties of Carpobrotus edulis (L.) bolus leaf used for the management of common infections in HIV/AIDS patients in Eastern Cape Province," BMC Complement. Altern. Med. 12(1), 215. DOI: 10.1186/1472-6882-12-215.

Oueslati, S., R. Ksouri, H. Falleh, A. Pichette, C., and J. Legault. (2012). "Phenolic content, antioxidant, anti-inflammatory and anticancer activities of the edible halophyte Suaeda fruticosa Forssk," Food Chem. 132(2), 943-947.

Pain, C. F., and Abdelfattah, M. A. (2014). "Landform evolution in the arid northern United Arab Emirates: Impacts of tectonics, sea level changes and climate," Catena. DOI: 10.1016/j.catena.2014.09.011.

Popp, M. (1984). "Chemical composition of Australian mangroves I. Inorganic ions and organic acids," Zeitschrift für Pflanzenphysiologie 113(5), 395-409. DOI: 10.1016/S0044-328X(84)80096-3.

Ran, H., Zhang, J., Gao, Q., Lin, Z., and Bao, J. (2014). “Analysis of biodegradation performance of furfural and 5-hydroxymethylfurfural by Amorphotheca resinae ZN1," Biotechnology for Biofuels 7, 51. DOI: 10.1186/1754-6834-7-51.

Rashid, S. (1994). "Chemical composition of Suaeda fruticosa and antibacterial activities of some of its extracts," M. Sc. Thesis, Islamia University Bahawalpur, Pakistan.

Rodrigues, M. J., Gangadhar, K. N., Vizetto-Duarte, C., Wubshet, S. G., Nyberg, N. T., Barreira, L., Varela, J., and Custódio, L. (2014). "Maritime halophyte species from southern Portugal as sources of bioactive molecules," Mar. Drugs 12(4), 2228-2244. DOI: $10.3390 / \mathrm{md} 12042228$.

Rozema, J., and Flowers, T. J. (2008). "Crops for a salinized world," Science 322, 14781480. DOI: $10.1126 /$ science.1168572.

Severo, I. A., Siqueira, S. F., Deprá, M. C., Maroneze, M. M., Zepka, L. Q., and JacobLopes, E. (2019). "Biodiesel facilities: What can we address to make biorefineries commercially competitive?" Renewable and Sustainable Energy Reviews 112, 686705. DOI: 10.1016/j.rser.2019.06.020.

Shaltout, K. H., El Keblawy, A. A., and Mousa, M. T. (2008). "Evaluation of the range plants quality and palatability for camel grazing in the United Arab Emirates," $J$. Camel. Sci. 1, 1-13.

Singh, O., and Gabani, P. (2011). "Extremophiles: Radiation resistance microbial reserves and therapeutic implications," J. Appl. Microbiol. 110(4), 851-861. DOI: 10.1111/j.1365-2672.2011.04971.x.

Sluiter, A., Hames, B., Ruiz, R., Scarlata, C., Sluiter, J., and Templeton, D. (2008a). "Determination of ash in biomass," NREL/TP-510-42622, National Renewable Energy Laboratory, Golden, Co.

Sluiter, A., Hames, B., Ruiz, R., Scarlata, C., Sluiter, J., Templeton, D., and Crocker, D. (2008b). "Determination of structural carbohydrates and lignin in biomass," NREL/TP-510-42618, National Renewable Laboratory, Golden, CO. 
Sluiter, A., Ruiz, R., Scarlata, C., Sluiter, J., and Templeton, D. (2008c). "Determination of extractives in biomass," NREL/TP-510-42619, National Renewable Energy Laboratory, Golden, CO.

Tigrine-Kordjani, N., Meklati, B., and Chemat, F. (2006). "Analysis by gas chromatography-mass spectrometry of the essential oil of Zygophyllum album L., an aromatic and medicinal plant growing in Algeria," Int. J. Aromather. 16, 187-191. DOI: 10.1016/j.ijat.2006.09.008.

Tigrine-Kordjani, N., Meklati, B. Y., and Chemat, F. (2011). "Contribution of microwave accelerated distillation in the extraction of the essential oil of Zygophyllum album L." Phytochem. Anal. 22(1), 1-9. DOI: 10.1002/pca.1236.

Towhidi, A., and Zhandi, M. (2007). "Chemical composition, in vitro digestibility and palatability of nine plant species for dromedary camels in the province of Semnan, Iran," Egypt. J. Biol., 9(1).

Trabelsi, N., Megdiche, W., Ksouri, R., Falleh, H., Oueslati, S., Soumaya, B., Hajlaoui, H., and Abdelly, C. (2010). "Solvent effects on phenolic contents and biological activities of the halophyte Limoniastrum monopetalum leaves," LWT-Food Sci. Technol. 43(4), 632-639. DOI: 10.1016/j.lwt.2009.11.003.

Welch, B. L. (1978). "Relationships of soil salinity, ash, and crude protein in Atriplex canescens," J. Range Manage 31, 132-133.

Yang, M. H., Kim, N.-H., Heo, J.-D., Sung, S. H., and Jeong, E. J. (2014). "Hepatoprotective effects of Limonium tetragonum, edible medicinal halophyte growing near seashores," Pharmacogn. Mag., 10(Suppl 3), S563. DOI: 10.4103/0973-1296.139783.

Article submitted: April 4, 2019; Peer review completed: July 6, 2019; Revised version received and accepted: May 18, 2021; Published: June 15, 2021.

DOI: 10.15376/biores.16.3.5524-5537 